\title{
Association between GDF5 + 104T/C polymorphism and knee osteoarthritis in Caucasian and Asian populations: a meta-analysis based on case-control studies
}

Dong Jiang ${ }^{1}$, Zengtao Hao², Dongsheng Fan², Wen Guo ${ }^{1}$, Pengcheng $\mathrm{Xu}^{1}$, Chao Yin², Shuzheng Wen²* and Jihong Wang ${ }^{2^{*}}$ (D)

\begin{abstract}
Background: Osteoarthritis $(\mathrm{OA})$ is a degenerative joint disease with a complex genetic background. Variants in growth differentiation factor 5 (GDF5) have been reported to be associated with rheumatoid arthritis (RA) in several ethnic populations. The present study aimed to assess the association between the GDF5 +104T/C polymorphism and the susceptibility of the knee to OA through a meta-analysis of available case-control studies.

Methods: The PubMed and Science Direct citation databases were used to search electronic literature in order to identify studies published between January 2007 and July 2016 that evaluated the association between the GDF5 +104 T/C polymorphism and the susceptibility of the knee to OA. Different genetic models were used to assess the pooled and stratified data.

Results: A positive association was found in all pooled studies ( $\mathrm{OR}=0.808,95 \% \mathrm{Cl}=0.754-0.866, p<0.001)$. Regarding genotypes, significant associations were found using a dominant model (OR $=0.777,95 \% \mathrm{Cl}=0.708-0.852, p<0.001)$, a recessive model $(\mathrm{OR}=0.723,95 \% \mathrm{Cl}=0.623-0.839, p<0.001)$, and an additive model (CC vs TT OR $=0.648,95 \%$ $\mathrm{Cl}=0.552-0.760, p<0.001$; CC vS CT OR $=0.801,95 \% \mathrm{Cl}=0.685-0.936, p=0.005)$. Meta-analysis data were stratified by ethnicity, and the GDF5 C allele was found to be positively associated with OA of the knee in both Caucasians and Asians, as were the GDF5 TC and CC genotypes. In addition, using an additive model, the CC genotype was found to be significantly associated with OA of the knee in both Caucasians and Asians when comparing CC vs TT genotypes, but not in Caucasians when comparing $T T$ vs $C T$ genotypes.
\end{abstract}

Conclusions: Meta-analysis results indicated that the GDF5 +104T/C polymorphism is a protective factor for OA among Caucasian and Asian populations.

Keywords: Meta-analysis, Osteoarthritis, Polymorphism, GDF5

\section{Background}

Osteoarthritis $(\mathrm{OA})$ is a chronic and progressive condition causing pain and disability worldwide and is regarded as a disease of the entire joint $[1,2]$. Obesity, age, and joint injury are the major risk factors for OA of the knee $[3,4]$. In addition, heritability studies have shown that genetic components account for approximately half of the risk for

\footnotetext{
* Correspondence: wenshuzheng54@sina.com; wangjihong54@sina.com ${ }^{2}$ Department of Hand and Microsurgery II, the Second Affiliated Hospital of Inner Mongolia Medical University, Hohhot 010030, China

Full list of author information is available at the end of the article
}

development of OA of the knee [5-7]. Understanding the genetic factors that influence progression of the disorder is important for the development of therapies to prevent or attenuate the pathogenesis of knee OA [8].

The genetic background of knee OA likely involves multiple genes that encode proteins with significant functions in the underlying disease process. The growth differentiation factor 5 (GDF5) gene contains three introns and is located on chromosome 20q11.2, spanning $21.43 \mathrm{~kb}$ from 34042573 to 34021146 . The GDF5 protein is encoded by the reverse strand 
(Entrez Gene, http://www.ncbi.nlm.nih.gov/IEB/Research/ Acembly/av.cgi). Proteins encoded by GDF5 are members of the TGF-beta superfamily and the bone morphogenetic protein (BMP) family. Proteins of this group contain a polybasic proteolytic processing site, which can produce a mature protein with seven conserved cysteine residues [9]. These proteins have been shown to be regulators of cell growth and differentiation in both embryonic and adult tissues. Variants of GDF5 are associated with chondrodysplasia, acromesomelic dysplasia, and brachydactyly [10-12], indicating that GDF5 may play a protective role in skeletal development. In addition, the GDF5 $+104 T / C$ single-nucleotide polymorphism (SNP) in the $5^{\prime}$ untranslated region (UTR) of this gene may result in increased risk of OA. Recently, a number of research groups have reported associations between the GDF5 +104T/C SNP and the susceptibility to OA in different ethnic populations. Weak or a complete lack of association in different ethnic populations has been reported by other groups, which may be the result of publication bias, differences in allele frequencies between races, or limited sample sizes.

Although several meta-analyses based on differences in strategies have highlighted a possible association between the GDF5 +104T/C SNP and knee OA, all meta-analyses did not distinguish between case-control and cohort studies [13-15]. More recently, several new studies have also reported an association between the GDF5 $+104 T / C$ SNP and risk of knee OA $[16,17]$. In the present study, a meta-analysis was performed to evaluate the contribution of the GDF5 $+104 T / C$ polymorphism to the susceptibility of the knee to OA in different ethnic populations.

\section{Methods}

\section{Study identification and selection}

The PubMed and Science Direct citation databases were used to search electronic literature to identify studies published between January 2007 and July 2016 that evaluated the association between the GDF5 $+104 T / C$ polymorphism and the susceptibility of the knee to OA. Combinations of keywords used in the search and entered as Medical Subject Headings (MeSH) were as follows: ("osteoarthritis" or "GDF5" or "polymorphism" or "GDF5 +104T/C"); ("genetics" or "OA" or "rs143383"); and ("polymorphism" or "polymorphisms").

\section{Inclusion and exclusion criteria}

Data were collected from fully published articles, excluding any conference or meeting abstracts. Inclusion criteria were as follows: (a) evaluation of the association between GDF5 rs143383 polymorphism with susceptibility to knee OA; (b) case-controlled study design based on unrelated individuals; and (c) case and control groups having sufficient genotypic data ( $T$ and $C$ ) and/or sufficient allelic data $(T T, T C$, and $C C)$ for estimation of odds ratios (OR) with $95 \%$ confidence interval $(95 \% \mathrm{CI})$. Exclusion criteria were as follows: (a) overlapping data; (b) genotype frequencies or numbers not reliably ascertained; (c) cohort or family-based study design, because the design and analysis of the study are based on linkage; and (d) review paper or abstract.

\section{Data extraction}

The following information was extracted: (a) name of the first author, (b) year of publication, (c) ethnicity of the studied population, (d) the numbers of cases and controls of GDF5 polymorphism, and (e) Hardy-Weinberg equilibrium (HWE) of controls.

\section{Statistical analysis}

Allele frequencies of the $G D F 5+104 T / C$ polymorphism from each respective study were determined by the allele counting method. HWE was used to examine the deviation of data associated with the GDF5 rs143383 SNP in the knee OA control groups using Fisher's exact test. If the $p$ value of HWE was not greater than 0.05 , the control group was considered to be in disequilibrium. To evaluate the strength of association between the GDF5 rs 143383 polymorphism and the susceptibility of the knee to OA, pooled ORs and their $95 \%$ CIs were determined for each study, and within-study and between-study heterogeneity were evaluated by Cochran's $Q$ statistic [18].

The pooled ORs were performed for allelic contras, dominant, recessive, and additive models. If a $p$ value for a particular $Q$ statistic was less than 0.10 , the random effects model was used [19]. The $I^{2}$ measure $\left(I^{2}=\right.$ $100 \% x(Q-d f) / Q)$ was used to quantify the effect of heterogeneity [20]. $I^{2}$ ranges between 0 and $100 \%$, which, respectively, represents the proportion of interstudy variability attributable to heterogeneity rather than chance (low, 0-25\%; moderate, 25-50\%; large, $50-75 \%$; and very large, $>75 \%)$. When $I^{2}$ is greater than $50 \%$, a study should be eliminated that performs for $I^{2}$ values to reach less than $25 \%$ [21].

Sensitivity analysis was then performed by excluding studies violating HWE [22].

To evaluate publication bias, funnel plots were determined. However, due to the limited number of studies, Egger's linear regression test was used to evaluate the bias [23]. When the pooled study groups are homogenous, the random effects and fixed effects models are similar. However, if this is not the case, the random effects model usually provides wider CIs than the fixed effects model [19]. In the present study, statistical manipulations were performed using Stata 11 software (Stata Corporation, College Station, TX). 


\section{Results}

Fifty-two articles that evaluated the association between GDF5 $+104 T / C$ polymorphism and the susceptibility of the knee to OA were identified (Fig. 1). Twenty-eight papers were excluded due to data missing, not being a casecontrol study, genotype distribution in the controls being inconsistent with HWE, previous meta-analysis studies, or missing data. Seven articles met the inclusion criteria [17, 24-29]. Among these, one study reported on two populations (Chinese and Japanese; UK and Spanish; two different populations in the UK) that were considered as two separate studies [24, 25, 28]. The seven identified papers included nine case-control studies involving 3319 knee OA patients and 4987 controls that were conducted in Caucasian and Asian populations.

Characteristics of the GDF5 +104T/C studies included in the present meta-analysis are listed in Table 1. The results showed a positive association in all pooled studies $(\mathrm{OR}=0.808,95 \% \mathrm{CI}=0.754-0.866, p<0.001$ ) (Table 2). Regarding genotypes, a significant association was found using a dominant model (OR $=0.777,95 \%$ $\mathrm{CI}=0.708-0.852, p<0.001)$, a recessive model $(\mathrm{OR}=0.723$, $95 \% \mathrm{CI}=0.623-0.839, p<0.001)$, and an additive model $(C C$ vs $T T$ OR $=0.648,95 \% \mathrm{CI}=0.552-0.760, p<0.001$; $C C$ vs $C T$ OR $=0.801,95 \% \mathrm{CI}=0.685-0.936, p=0.005$ ). After meta-analysis data were stratified by ethnicity, the $C$ allele of GDF5 was found to be positively associated with knee $\mathrm{OA}$ in Caucasians $(\mathrm{OR}=0.872,95 \% \mathrm{CI}=$ 0.794-0.957, $p=0.004)$ and Asians (OR $=0.738,95 \%$ $\mathrm{CI}=0.665-0.818, p<0.001)$. In addition, the GDF5 TC and $C C$ genotypes were found to be positively associated with knee OA in Caucasians $(\mathrm{OR}=0.853,95 \%=0.749$ $0.972, p=0.017)$ and Asians $(\mathrm{OR}=0.706,95 \% \mathrm{CI}=$ $0.619-0.806, p<0.001)$. Using an additive model, the $C C$ genotype was found to be significantly associated with knee $\mathrm{OA}$ in Caucasians $(\mathrm{OR}=0.648,95 \% \mathrm{CI}=$ $0.552-0.760, p=0.007)$ and Asians (OR $=0.518,95 \%$ $\mathrm{CI}=0.402-0.668, p<0.001)$ when comparing $C C$ vs $T T$ genotypes, and when comparing $T T$ vs $C T$ genotypes $(\mathrm{OR}=0.743,95 \% \mathrm{CI}=0.578-0.955, p=0.021)$, but not significantly associated with knee OA in Caucasians when comparing $T T$ vs $C T$ genotypes $(\mathrm{OR}=0.840,95 \%$ $\mathrm{CI}=0.685-1.026, p=0.088)($ Table 2$)$.

\section{Heterogeneity and publication bias}

The between-study heterogeneity in terms of the ORs of the $G D F 5+104 T / C$ polymorphism were found in all subjects and thus, meta-analysis of the GDF5 $+104 T / C$ polymorphism was performed using a random effects model for all subjects, with the exception of the dominant model, which was analyzed using a fixed effects model $\left(I^{2}=53.2 \%\right)$ (Table 2).

A publication bias was identified in the present study (Fig. 2), due to the disproportionate number of articles reporting positive results. Evidence for this was found using recessive and additive models, as the $p$ value of Egger's regression was less than 0.1. In view of this, the "trim and fill" method was used in order to adjust for publication bias in the present study. Adjusted ORs obtained using the "trim and fill" method remained statistically significant (data not shown).

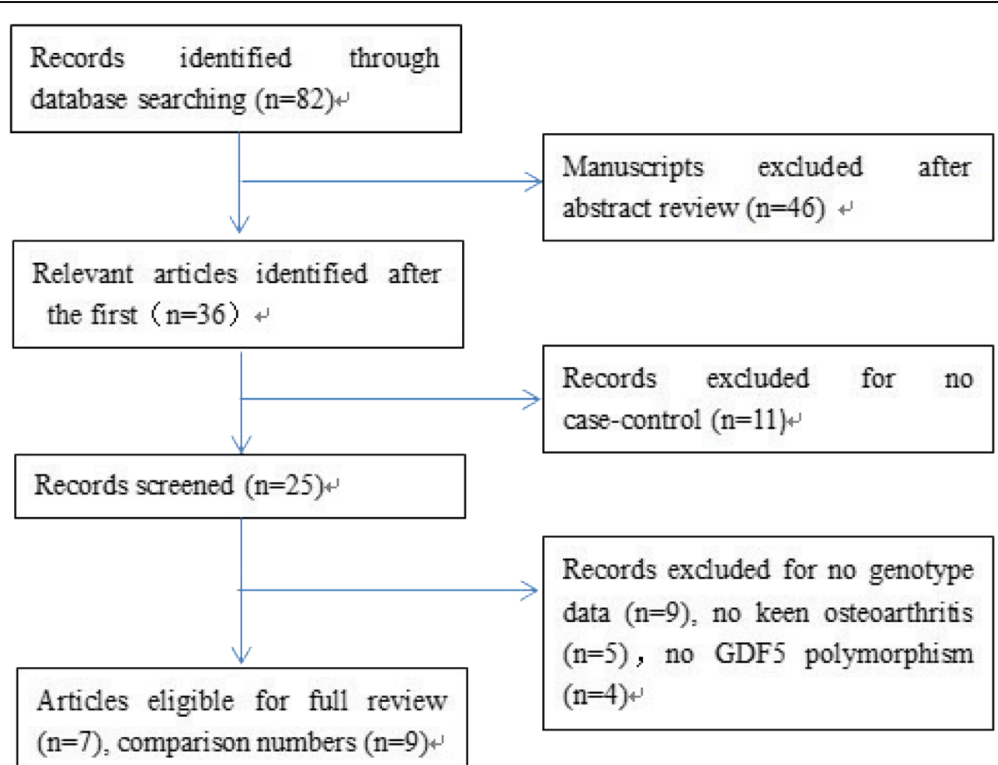

Fig. 1 Flow chart of studies of GDF5 rs 143383 polymorphism in the meta-analysis 
Table 1 Characteristics of the studies of GDF5 rs 143383 polymorphism included in the meta-analysis

\begin{tabular}{|c|c|c|c|c|c|c|c|}
\hline \multirow[t]{2}{*}{ First author } & \multirow[t]{2}{*}{ Year } & \multirow[t]{2}{*}{ Ethnicity } & \multicolumn{2}{|c|}{ Numbers } & \multicolumn{2}{|c|}{ RA/controls (allele) } & \multirow[t]{2}{*}{ HWE $(P$} \\
\hline & & & $\overline{\mathrm{OA}}$ & $\overline{\text { Controls }}$ & $\bar{T}$ & $C$ & \\
\hline Southam et al. ${ }^{a}$ & 2007 & Caucasian & 349 & 822 & $450 / 1020$ & $248 / 624$ & 0.262 \\
\hline Southam et al. ${ }^{a}$ & 2007 & Caucasian & 274 & 1196 & $340 / 1441$ & 208/951 & 0.550 \\
\hline Miyamoto et al. ${ }^{a}$ & 2007 & Asian & 718 & 861 & $1131 / 1276$ & $305 / 446$ & 0.966 \\
\hline Miyamoto et al. ${ }^{\mathrm{b}}$ & 2007 & Asian & 313 & 485 & $491 / 681$ & $135 / 289$ & 0.283 \\
\hline Tsezou et al. & 2007 & Caucasian & 251 & 268 & $316 / 323$ & $186 / 213$ & 0.669 \\
\hline Valdes et al. & 2009 & Caucasian & 735 & 654 & $987 / 805$ & $483 / 487$ & 0.320 \\
\hline Cao et al. & 2010 & Asian & 276 & 298 & $415 / 431$ & $137 / 165$ & 0.360 \\
\hline Tawonsawatruk et al. & 2011 & Asian & 103 & 103 & $117 / 113$ & $63 / 93$ & 0.424 \\
\hline Mishra et al. & 2013 & Asian & 300 & 300 & $378 / 328$ & $222 / 272$ & 0.188 \\
\hline
\end{tabular}

Letters ${ }^{\mathrm{a}}$ and ${ }^{\mathrm{b}}$ denote an independent study in one article HWE Hardy-Weinberg equilibrium

\section{Sensitivity analyses}

The HWE-violating studies were excluded in order to perform sensitivity analyses, and the stability of the results was then evaluated. Departure from HWE was observed in the control of one study (Valdes et al. [28]). After excluding this study, the corresponding ORs did not change substantially in all models, suggesting that the results of the present meta-analysis are stable (data not shown).

\section{Discussion}

The association between the $+104 \mathrm{C}$ allele at the rs143383 polymorphism in the GDF5 gene and OA of the knee has been documented in genome-wide association studies (GWAS), with inconsistent results in different case-controls. Meta-analysis is known to be a suitable methodology for detecting small effects in genetic association studies, and the present study was designed in order to update and investigate the results associating the $G D F 5+104 T / C$ polymorphism with the susceptibility to $\mathrm{OA}$ of the knee in different ethnic populations. Seven studies relating to $G D F 5+104 T / C$ polymorphism were included in the present meta-analysis.

Significant association between the GDF5 +104T/C polymorphism and the susceptibility to OA of the knee has been demonstrated in the present study. These results indicate that the GDF5 rs143383 C allele was significantly related to $\mathrm{OA}$ of the knee in Caucasian and Asian subjects. GDF5 TC and CC genotypes were found to be significantly related to $\mathrm{OA}$ of the knee in Caucasian and Asian subjects. In addition, the GDF5 rs143383 TT

Table 2 Meta-analysis of the association between GDF5 rs 143383 polymorphism and OA susceptibility

\begin{tabular}{|c|c|c|c|c|c|c|c|c|c|c|c|c|}
\hline \multirow[t]{2}{*}{ Comparison } & \multirow{2}{*}{$\begin{array}{l}\text { Ethnic } \\
\text { group }\end{array}$} & \multirow[t]{2}{*}{ Studies } & \multicolumn{2}{|c|}{ Sample size } & \multicolumn{5}{|c|}{ Test of association } & \multicolumn{3}{|c|}{ Test of heterogeneity } \\
\hline & & & $\overline{\mathrm{OA}}$ & Control & $\overline{\mathrm{OR}}$ & $95 \% \mathrm{Cl}$ & & $p$ value & Model & Q test & $p$ value & $P^{2}(\%)$ \\
\hline Allelic contrast & Overall & 9 & 3319 & 4987 & 0.808 & 0.754 & 0.866 & 0.000 & $R$ & 10.12 & 0.698 & 0 \\
\hline \multirow[t]{2}{*}{ ( $T$ vs $C$ allele) } & Caucasian & 4 & 1609 & 2940 & 0.872 & 0.794 & 0.957 & 0.004 & & 1.43 & 0.518 & 0 \\
\hline & Asian & 5 & 1710 & 2047 & 0.738 & 0.665 & 0.818 & 0.000 & & 3.25 & 0.257 & 21 \\
\hline Dominant model & Overall & 9 & 3319 & 4987 & 0.777 & 0.708 & 0.852 & 0.000 & $F$ & 17.1 & 0.029 & 53.2 \\
\hline \multirow[t]{2}{*}{$(T C+C C$ vs $T T)$} & Caucasian & 4 & 1609 & 2940 & 0.853 & 0.749 & 0.972 & 0.017 & & 5.99 & 0.112 & 49.9 \\
\hline & Asian & 5 & 1710 & 2047 & 0.706 & 0.619 & 0.806 & 0.000 & & 7.16 & 0.128 & 44.1 \\
\hline Recessive model & Overall & 9 & 3319 & 4987 & 0.723 & 0.623 & 0.839 & 0.000 & $R$ & 6.66 & 0.574 & 0 \\
\hline \multirow[t]{2}{*}{$(C C$ vs $T C+T T)$} & Caucasian & 4 & 1609 & 2940 & 0.797 & 0.659 & 0.965 & 0.02 & & 1.60 & 0.659 & 0 \\
\hline & Asian & 5 & 1710 & 2047 & 0.621 & 0.489 & 0.789 & 0.000 & & 2.57 & 0.633 & 0 \\
\hline Additive model & Overall & 9 & 3319 & 4987 & 0.648 & 0.552 & 0.760 & 0.000 & $R$ & 5.84 & 0.665 & 0 \\
\hline \multirow[t]{2}{*}{$(C C$ vs TT) } & Caucasian & 4 & 1609 & 2940 & 0.754 & 0.613 & 0.927 & 0.007 & & 0.15 & 0.986 & 0 \\
\hline & Asian & 5 & 1710 & 2047 & 0.518 & 0.402 & 0.668 & 0.000 & & 0.69 & 0.953 & 0 \\
\hline Additive model & Overall & 9 & 3319 & 4987 & 0.801 & 0.685 & 0.936 & 0.005 & $R$ & 9.64 & 0.291 & 17 \\
\hline \multirow[t]{2}{*}{ (CC vs TC) } & Caucasian & 4 & 1609 & 2940 & 0.84 & 0.688 & 1.026 & 0.088 & & 4.49 & 0.213 & 33.2 \\
\hline & Asian & 5 & 1710 & 2047 & 0.743 & 0.578 & 0.955 & 0.021 & & 4.63 & 0.328 & 13.6 \\
\hline
\end{tabular}




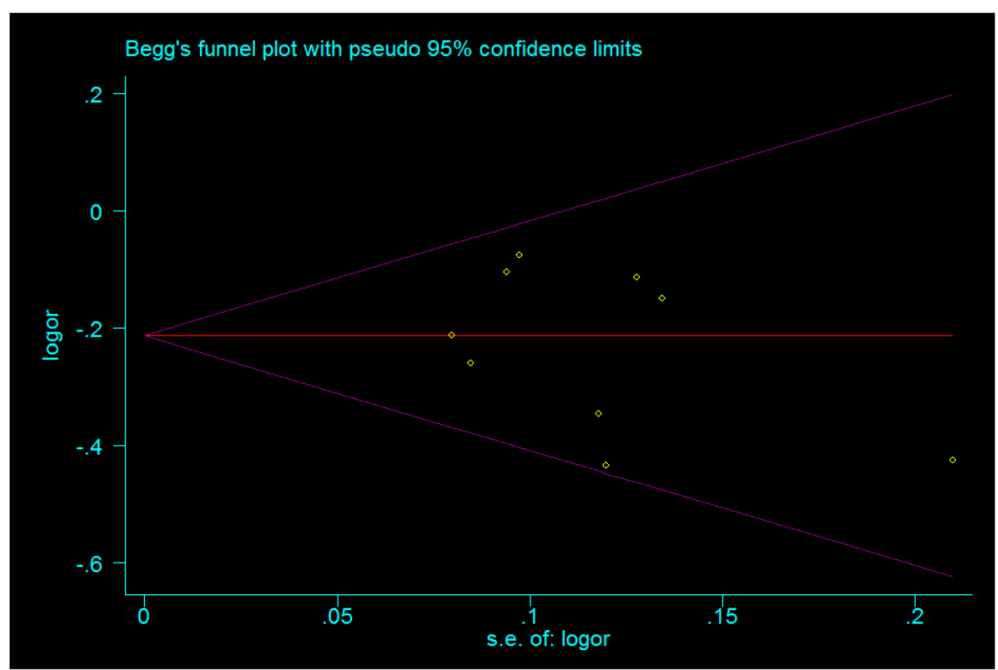

Fig. 2 Funnel plot of the meta-analysis of OA risk and the rs 143383 polymorphism

genotype was found to be significantly related to OA of the knee in Caucasian and Asian subjects, although not significantly related to OA of the knee in Caucasians when evaluated using an additive model $(C C$ vs $T C)$.

The GDF5 gene is located on chromosome 20q11.2 and spans $21.43 \mathrm{~kb}$, from 34042573 to 34021146 , on the reverse strand. The protein encoded by GDF5 is a member of the bone morphogenetic protein (BMP) family. GDF5 gene variants are associated with brachydactyly, chondrodysplasia, and acromesomelic dysplasia, indicating that the GDF5 gene product plays a critical role in skeletal development [30]. Several animal studies have confirmed data supportive of a key role for GDF5 [31-33]. In animals with GDF5 variants, multiple joint abnormalities have been reported, including tendon anomaly, soft tissue deformities, and decreases in the appendicular skeleton. Overall, these results demonstrate that variants of GDF5 may play a crucial role in the pathogenesis of OA.

Heterogeneity in different ethnic populations is a potential problem that is further complicated by allelic frequencies of different susceptibility genes [34]. In the present study, significant heterogeneity was identified among different ethnic groups. To evaluate this further, ethnicity was used to stratify the studies included in order to clarify the heterogeneity. The results indicated that part of the heterogeneity identified was attenuated. In addition, every study with the unique criteria defined the cases, which may have resulted in the observed heterogeneity. Some of the studies used in the evaluation used the ACR criteria and/or K/L classification to define the respective cases of $\mathrm{OA}$, while other studies defined OA using the TKR criteria. These differences between the control groups and the key characteristics of the participants may also result in the observed heterogeneity in the magnitude of the genetic effects [35]. Recruiting a matched control group may contribute to the magnitude of heterogeneous genetic effects [35]. Additional factors may also be taken into consideration in order to identify heterogeneity in the event additional data were available.

Previous meta-analysis studies have reported an association between GDF5 $+104 T / C$ polymorphism and the susceptibility to OA of the knee in Asians and Caucasians. These studies also reported that the GDF5 rs143383 C allele serves as a protective factor for $\mathrm{OA}$ in Caucasians $(\mathrm{OR}=0.87, p<0.001)$ and Asians $(\mathrm{OR}=0.78, p=0.003)$ [14]. Rui et al. reported an association between CDF5 rs143383 polymorphism and knee OA, hip OA, and hand OA using random or fixed effects models [13], although the findings did not distinguish between case-control and cohort studies, further complicating the heterogeneity among different studies.

In the present meta-analysis, the incidence of the GFD5 $C$ allele was found to vary among different ethnicities, from $19.8 \%$ in Asian to $23.3 \%$ in Caucasian populations. In terms of controls, the frequencies of the GDF5 $C$ allele in the Asian and European populations were 28.1 and $45.7 \%$, respectively. Although a comprehensive meta-analysis was performed, some limitations should be acknowledged in the present study. Some studies were excluded in spite of establishing search criteria, as raw data is insufficient. In addition, between-study heterogeneity and publication bias may influence the results in the present meta-analysis.

\section{Conclusions}

In conclusion, the meta-analysis confirmed that the GDF5 $+104 T / C$ polymorphism can confer susceptibility to knee OA with a protective association in the subjects. 


\section{Abbreviations}

BMP: Bone morphogenetic protein; Cls: Confidence intervals; GDF5: Growth differentiation factor 5; GWAS: Genome-wide association studies; HWE: HardyWeinberg equilibrium; MeSH: Medical Subject Headings; OA: Osteoarthritis; SNP: Single-nucleotide polymorphism; UTR: Untranslated region

\section{Acknowledgements}

None.

\section{Funding}

None.

\section{Availability of data and materials}

As this paper is a meta-analysis, there are no patient data sets. The search strategy was for the study selection, which supports the conclusion of the meta-analysis.

\section{Authors' contributions}

DJ, ZH, and DF conceived of the design of the study. WG, PX, CY, and JW performed and collected the data and contributed to the design of the study. DJ, SW, and ZH prepared and revised the manuscript. All authors read and approved the final content of the manuscript.

\section{Competing interests}

The authors declare that they have no competing interests.

\section{Consent for publication}

Not applicable.

\section{Ethics approval and consent to participate}

Not applicable; this meta-analysis does not involve research on humans.

\section{Author details}

${ }^{1}$ Inner Mongolia Medical University, Hohhot 010000, People's Republic of China. ${ }^{2}$ Department of Hand and Microsurgery II, the Second Affiliated Hospital of Inner Mongolia Medical University, Hohhot 010030, China.

\section{Received: 22 July 2016 Accepted: 5 September 2016}

\section{Published online: 23 September 2016}

\section{References}

1. Murphy L, Helmick CG. The impact of osteoarthritis in the United States: a population-health perspective. Am J Nurs. 2012:112:S13-19.

2. O'Conor CJ, Ramalingam S, Zelenski NA, Benefield HC, Rigo I, Little D, Wu CL, Chen D, Liedtke W, McNulty AL, Guilak F. Cartilage-specific knockout of the mechanosensory ion channel TRPV4 decreases age-related osteoarthritis. Sci Rep. 2016:6:29053.

3. Guilak F. Biomechanical factors in osteoarthritis. Best Pract Res Clin Rheumatol. 2011:25:815-23.

4. van Tunen JA, Dell'Isola A, Juhl C, Dekker J, Steultjens M, Lund H. Biomechanical factors associated with the development of tibiofemoral knee osteoarthritis: protocol for a systematic review and meta-analysis. BMJ Open. 2016;6:e011066.

5. Hochberg MC, Yerges-Armstrong L, Yau M, Mitchell BD. Genetic epidemiology of osteoarthritis: recent developments and future directions. Curr Opin Rheumatol. 2013;25:192-7.

6. Loughlin J. The genetic epidemiology of human primary osteoarthritis: current status. Expert Rev Mol Med. 2005:7:1-12.

7. MacGregor AJ, Li Q, Spector TD, Williams FM. The genetic influence on radiographic osteoarthritis is site specific at the hand, hip and knee. Rheumatology (Oxford). 2009;48:277-80.

8. Vincent TL. Targeting mechanotransduction pathways in osteoarthritis: a focus on the pericellular matrix. Curr Opin Pharmacol. 2013:13:449-54.

9. Martinez-Garcia M, Garcia-Canto E, Fenollar-Cortes M, Aytes AP, TrujilloTiebas MJ. Characterization of an acromesomelic dysplasia, Grebe type case: novel mutation affecting the recognition motif at the processing site of GDF5. J Bone Miner Metab. 2015. doi:10.1007/s00774-015-0693-z.

10. Al-Qattan MM, Al-Motairi MI, Al Balwi MA. Two novel homozygous missense mutations in the GDF5 gene cause brachydactyly type C. Am J Med Genet A. 2015;167:1621-6.
11. Farooq M, Nakai H, Fujimoto A, Fujikawa H, Kjaer KW, Baig SM, Shimomura Y Characterization of a novel missense mutation in the prodomain of GDF5, which underlies brachydactyly type $C$ and mild Grebe type chondrodysplasia in a large Pakistani family. Hum Genet. 2013;132:1253-64.

12. Khan S, Basit S, Khan MA, Muhammad N, Ahmad W. Genetics of human isolated acromesomelic dysplasia. Eur J Med Genet. 2016;59:198-203.

13. Zhang R, Yao J, Xu P, Ji B, Luck JV, Chin B, Lu S, Kelsoe JR, Ma J. A comprehensive meta-analysis of association between genetic variants of GDF5 and osteoarthritis of the knee, hip and hand. Inflamm Res. 2015;64: 405-14.

14. Pan F, Tian J, Winzenberg T, Ding C, Jones G. Association between GDF5 rs143383 polymorphism and knee osteoarthritis: an updated meta-analysis based on 23,995 subjects. BMC Musculoskelet Disord. 2014;15:404.

15. Liu J, Cai W, Zhang H, He C, Deng L. Rs143383 in the growth differentiation factor 5 (GDF5) gene significantly associated with osteoarthritis (OA)-a comprehensive meta-analysis. Int J Med Sci. 2013;10:312-9.

16. Xiao JL, Meng JH, Gan YH, Zhou CY, Ma XC. Association of GDF5, SMAD3 and RUNX2 polymorphisms with temporomandibular joint osteoarthritis in female Han Chinese. J Oral Rehabil. 2015:42:529-36.

17. Mishra A, Sanghi D, Maurya SS, Singh A, Srivastava RN, Sharma C, Raj S, Avasthi S, Parmar D. Association of polymorphism in growth and differentiation factor 5 gene with osteoarthritis knee. American Journal of Biochemistry \& Biotechnology. 2013. doi:10.1186/1471-2474-15-404.

18. Cochran WG. The combination of estimates from different experiments. Biometrics. 1954;10:101-29.

19. Dersimonian R, Nan L. Meta-analysis in clinical trials. Control Clin Trials. 1986; 7:177-88.

20. Higgins JPT, Thompson SG. Quantifying heterogeneity in a meta-analysis. Stat Med. 2002;21:1539-58.

21. Patsopoulos NA, Evangelou E, loannidis JP. Sensitivity of between-study heterogeneity in meta-analysis: proposed metrics and empirical evaluation. Int J Epidemiol. 2008;37:1148-57.

22. Thakkinstian A, McElduff P, D'Este C, Duffy D, Attia J. A method for metaanalysis of molecular association studies. Stat Med. 2005:24:1291-306.

23. Song F, Gilbody S. Bias in meta-analysis detected by a simple, graphical test. Increase in studies of publication bias coincided with increasing use of meta-analysis. BMJ. 1998;316:471

24. Miyamoto Y, Mabuchi A, Shi D, Kubo T, Takatori Y, Saito S, Fujioka M, Sudo A, Uchida A, Yamamoto S, Ozaki K, Takigawa M, Tanaka T, Nakamura Y, Jiang Q, Ikegawa S. A functional polymorphism in the $5^{\prime}$ UTR of GDF5 is associated with susceptibility to osteoarthritis. Nat Genet. 2007;39:529-33.

25. Southam L, Rodriquez-Lopez J, Wilkins JM, Pombo-Suarez M, Snelling S, Gomez-Reino JJ, Chapman K, Gonzalez A, Loughlin J. An SNP in the 5'-UTR of GDF5 is associated with osteoarthritis susceptibility in Europeans and with in vivo differences in allelic expression in articular cartilage. Hum Mol Genet. 2007;16:2226-32

26. Tawonsawatruk T, Changthong T, Pingsuthiwong S, Trachoo O, Sura T, Wajanavisit W. A genetic association study between growth differentiation factor 5 (GDF 5) polymorphism and knee osteoarthritis in Thai population. J Orthop Surg Res. 2011;6:47

27. Tsezou A, Satra M, Oikonomou P, Bargiotas K, Malizos KN. The growth differentiation factor 5 (GDF5) core promoter polymorphism is not associated with knee osteoarthritis in the Greek population. J Orthop Res. 2008;26:136-40,

28. Valdes AM, Spector TD, Doherty S, Wheeler M, Hart DJ, Doherty M. Association of the DWWA and GDF5 polymorphisms with osteoarthritis in UK populations. Ann Rheum Dis. 2009;68:1916-20.

29. Cao Z, Lee HS, Song JH, Yoon JW, Yong KP, Nam SW, Lee JY, Park WS. Growth differentiation factor 5 (GDF5) core promoter polymorphism is not associated with susceptibility to osteoarthritis of the knee in the Korean population. Korean J Pathol. 2010;44:404-9.

30. Francis-West PH, Abdelfattah A, Chen P, Allen C, Parish J, Ladher R, Allen S, MacPherson S, Luyten FP, Archer CW. Mechanisms of GDF-5 action during skeletal development. Development. 1999;126:1305-15.

31. Gallagher JA, Ranganath LR, Boyde A. Lessons from rare diseases of cartilage and bone. Curr Opin Pharmacol. 2015;22:107-14

32. Reynard LN, Loughlin J. The genetics and functional analysis of primary osteoarthritis susceptibility. Expert Rev Mol Med. 2013;15:e2

33. Ohta Y, Okabe T, Larmour C, Di Rocco A, Maijenburg MW, Phillips A, Speck NA Wakitani S, Nakamura T, Yamada Y, Enomoto-Iwamoto M, Pacifici M, Iwamoto M. Articular cartilage endurance and resistance to osteoarthritic changes require transcription factor Erg. Arthritis Rheumatol. 2015;67:2679-90. 
34. Lee M, Aggen SH, Otowa T, Castelao E, Preisig M, Grabe HJ, Hartman CA, Oldehinkel AJ, Middeldorp CM, Tiemeier H, Hettema JM. Assessment and characterization of phenotypic heterogeneity of anxiety disorders across five large cohorts. Int J Methods Psychiatr Res. 2016. doi:10.1002/mpr.1519.

35. Evangelou E, Chapman K, Meulenbelt I, Karassa FB, Loughlin J, Carr A, Doherty M, Doherty S, Gomez-Reino JJ, Gonzalez A, Halldorsson BV Hauksson VB, Hofman A, Hart DJ, Ikegawa S, Ingvarsson T, Jiang Q, Jonsdottir I, Jonsson H, Kerkhof HJ, Kloppenburg M, Lane NE, Li J, Lories RJ, van Meurs JB, Nakki A, Nevitt MC, Rodriguez-Lopez J, Shi D, Slagboom PE, Stefansson K, Tsezou A, Wallis GA, Watson CM, Spector TD, Uitterlinden AG Valdes AM, loannidis JP. Large-scale analysis of association between GDF5 and FRZB variants and osteoarthritis of the hip, knee, and hand. Arthritis Rheum. 2009;60:1710-21.

Submit your next manuscript to BioMed Central and we will help you at every step:

- We accept pre-submission inquiries

- Our selector tool helps you to find the most relevant journal

- We provide round the clock customer support

- Convenient online submission

- Thorough peer review

- Inclusion in PubMed and all major indexing services

- Maximum visibility for your research

Submit your manuscript at www biomedcentral com/submit 